\title{
Sialolit: 3 olgunun klinik, radyografik ve ultrasonografik bulguları ile birlikte değerlendirilmesi
}

\author{
Melih Özdede, ${ }^{1,{ }^{*}}$ Nur Hacıosmanoğlu, ${ }^{1}$ Elif Kaya, ${ }^{1}$ \\ Halil Özer, ${ }^{2}$ Emre Akın, ${ }^{2}$ Anıl Seçkin,, ${ }^{3}$ \\ Sharif Rzayev ${ }^{3}$ \\ ${ }^{1}$ Ağız, Diş ve Çene Radyolojisi Anabilim Dalı, \\ Gazi Üniversitesi Diş Hekimliği Fakültesi, ${ }^{2}$ Radyoloji Anabilim

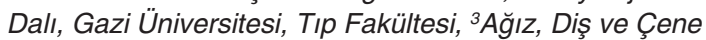 \\ Cerrahisi Anabilim Dalı, Gazi Üniversitesi Diş Hekimliği \\ Fakültesi, Ankara, Türkiye
}

\section{Özet}

TANITIM: Sialolitler (tükürük bezi taşı) tükürük bezinde veya kanalında oluşan kalsifiye tıkanıklıklardır. Tükürük bezlerinin en sık görülen rahatsızlıkları içinde yer alırlar. Sialolitlerin büyük bir kısmı submandibular bezde meydana gelmektedir ve her yaşta izlenebilmektedir. Klinik muayene ile birlikte konvansiyonel radyografi, ultrasonografi (USG) ve bilgisayarlı tomografi (BT) tanıda kullanılan yöntemlerdendir.

OLGU BiLDiRimi: Birinci olguda 66 yaşındaki kadın hastadan dental nedenlerle istenilen panoramik radyografta, sağ mandibula korpusunun hemen altında ve sol mandibula angulus bölgesinde radyoopak oluşumlar izlendi. Ultrasonografik incelemede bu oluşumların sialolit olduğu belirlendi. Herhangi bir semptomu bulunmayan hasta periyodik takibe alındı. Íkinci olguda 61 yaşındaki erkek hastanın intraoral muayenesinde, ağız tabanında sol submandibular bez bölgesinde sert kitleler palpe edildi ve sol Wharton kanalında tükürük akışının olmadığı gözlemlendi. Panoramik ve alt oklüzal radyograflarda izlenen radyoopasiteler üzerine istenen ultrasonografide sialolit ön tanısı doğrulandı ve sialolitler intraoral olarak eksize edildi. Üçüncü olguda, kliniğimize sağ yanak ve kulak bölgesinde yemek yerken oluşan ağrı şikayetiyle başvuran 55 yaşındaki kadın hastanın intraoral muayenesinde Stenon kanal ağzında püy akışı izlendi. Bunun üzerine istenen ultrasonografide sialolit tespit edildi ve enfekte olan sağ parotis bezinin heterojen ekojenitede olduğu izlendi. Genel anestezi altında cerrahi eksizyon yapıldı.

Sonuç: Sialolitlerin teşhisinde doğru görüntüleme yönteminin seçilmesi ve yorumlanması büyük önem taşımaktadır; teşhis ve tedavi aşamaları multidisipliner yaklaşım gerektirir.

Anahtar Kelimeler: Panoramik radyografi; siyalolitler, ultrasonografi

Makale gönderiliş tarihi: 25 Haziran 2014; Yayına kabul tarihi: 23 Ocak 2015 *iletișim: Melih Özdede, Gazi Üniversitesi Diş Hekimliği Fakültesi, Ağız, Diș ve Çene Radyolojisi Anabilim Dalı, 82. Sokak, 06510, Emek, Ankara, Türkiye; e-posta: melih673@gmail.com
KaynaK Göstermek İçin: Özdede M, Hacıosmanoğlu N, Kaya E, Özer H, Akın E, Seçkin A ve ark. Sialolit: 3 olgunun klinik, radyografik ve ultrasonografik bulguları ile birlikte değerlendirilmesi. Acta Odontol Turc 2016;33(1):35-8

ЕрітӧR: Güven Kayaoğlu, Gazi Üniversitesi, Ankara, Türkiye

YAYIN HAKKI: () 2016 Özdede ve ark. Bu eserin yayın hakkı Creative Commons Attribution License ile ruhsatlandırılmıştır. Sınırsız kullanım, dağıtım ve her türlü ortamda çoğaltım, yazarlar ve kaynağın belirtilmesi kaydıyla serbesttir.

[Abstract in English is at the end of the manuscript]

\section{Giriș}

Tükürük bezi parankiminin veya kanalının kalsiyum tuzları ile tıkanması sonucu meydana gelen kalsifiye yapı formasyonlarına sialolit denir. Sialolitler, tükürük bezi hastalıkları içerisinde en sık görülenidir. ${ }^{1-4}$ Sıklıkla submandibular bez veya kanalında gelişirler. ${ }^{5}$

Sialolitlerin teşhisinde anamnez, inspeksiyon, palpasyon ve tükürük akış miktarının ölçümü önem taşımaktadır. Hastalar genellikle yemek sırasında veya sonrasında tekrarlayan ağrı ve şişlik şikâyetiyle hekime başvururlar. ${ }^{6}$ Bazı vakalarda bez bölgesinde kulak ve boyuna doğru yayılan ağrılar olabilir. ${ }^{1}$ Sialolitler boyutları büyürse klinik olarak palpe edilebilirler. ${ }^{7}$

Sialolitler önemli derecede büyüdüklerinde kanalın tıkanmasına ve tükürük akışının azalmasına neden olabilirler. ${ }^{1}$ Tükürük akışı, hiposalivasyon hakkında objektif bilgi sağlayan sialometre ile ölçülebilir. Buna göre, stimüle edilmemiş tükürük akış hızının dakikadaki 0.3-0.4 $\mathrm{mL}$ arasındaki değeri normal, $0.2 \mathrm{~mL}$ 'den az bir değeri hiposalivasyon ve $0.1 \mathrm{~mL}$ 'nin altındaki değeri ise kserostomia bulgusu olarak değerlendirilmektedir. ${ }^{8,9}$

Klinik değerlendirmelere ek olarak radyografi, sialografi, ultrasonografi ve sintigrafi yöntemlerinden de yararlanılmaktadır. ${ }^{6}$ Son dönemde sialolitlerin görüntülenmesinde bilgisayarlı tomografi, manyetik rezonans sialografi ve sialoendoskopi yöntemleri de kullanılabilmektedir. ${ }^{10}$

\section{OLGU BiLdiRimi}

\section{Olgu 1}

66 yaşındaki kadın hasta kliniğimize çeşitli dental problemler nedeniyle başvurdu. Alınan anamnezde hastanın 
herhangi bir sistemik hastalığı olmadığı öğrenildi. Ekstraoral muayenede anormal bir bulguya rastlanmadı. Hastadan alınan panoramik radyografta sağ mandibular korpusun hemen altında ve sol mandibula angulus bölgesine süperpoze radyoopak oluşumlar izlendi (Resim 1).

Lenf nodu kalsifikasyonu ve sialolit ön tanısı konulan radyoopak oluşumlar ile ilgili anamnez derinleştirildi. Hasta ağrı, şişlik, ağızda kuruluk ve yanma hissi gibi şikâyetlerinin olmadığını bildirdi. Yapılan tükürük akış hızı testlerinde uyarıımamış tükürük akış hızının $0.34 \mathrm{~mL} / \mathrm{dk}$, uyarılmış tükürük akış hızı $1.5 \mathrm{~mL} / \mathrm{dk}$ olduğu belirlendi. Hasta, ultrasonografik inceleme için Gazi Üniversitesi Tıp Fakültesi Radyoloji Anabilim Dalı'na yönlendirildi.

Ultrasonografik görüntülemede sağ submandibular bez içerisinde yaklaşı $9.5 \mathrm{~mm}$ boyutunda ve sol submandibular tükürük bezi kanalı orta kesim lümeni içerisinde yaklaşık $7.5 \mathrm{~mm}$ boyutunda sialolit ile uyumlu ekojeniteler görüldü (Resim 1). Patolojik boyut artışı gösteren lenf nodu saptanmadı.

Herhangi bir semptom bulunmaması ve tükürük akış miktarının normal olması sebebi ile hasta periyodik takibe alındı. Üç ay sonra kontrol amaçlı gelen hastadan alınan ultrasonografi görüntülerinde sialolitlerin boyutunda değişiklik olmadığı saptandı ve hasta 3 aylık kontrollerine gelmesi konusunda bilgilendirildi.

\section{Olgu 2}

Sistemik anamnezinde psöriazis hastalığı olduğu öğrenilen ve hipotiroidi nedeni ile levotiroksin türü ilaç kullanan 61 yaşındaki erkek hasta kliniğimize çeşitli dental problemler nedeniyle başvurdu. Ekstraoral muayenede herhangi bir patolojik değişikliğe rastlanmadı. İntraoral muayenede sol Wharton kanalı ağzında tükürük akışı izlenmedi ve ağız tabanında sol submandibular bez bölgesinde sert kitleler palpe edildi. Hastadan alınan panoramik ve alt oklüzal radyografta sol submandibular bez bölgesinde iyi sınırlı iki adet radyoopak oluşum izlendi (Resim 2).

Hasta ileri görüntüleme amacıyla Gazi Üniversitesi Tıp Fakültesi Radyoloji Anabilim Dalı'na yönlendirildi. Yapılan ultrasonografik incelemede Wharton kanalında görülen iki adet iyi sınırlı hiperekojenite ile submandibular sialolit ön tanısı doğrulandı (Resim 2). Sialolitler intraoral cerrahi eksizyon ile çıkarıldı (Resim 3).

\section{Olgu 3}

Alınan anamnezde sistemik hastalığı ve sürekli kullandığı bir ilacı olmadığı öğrenilen 55 yaşındaki kadın hasta, sağ yanak ve kulak bölgesinde yemek yerken oluşan ağıı ve ağız içine iltihap akışı şikâyeti ile kliniğimize başvurdu. Hasta, hikâyesinde şişliğin yıllardır ara ara oluştuğunu ve iltihabın yaklaşık bir ayda geliştiğini belirtti. Ekstraoral muayenede hastanın yüzünde sağ

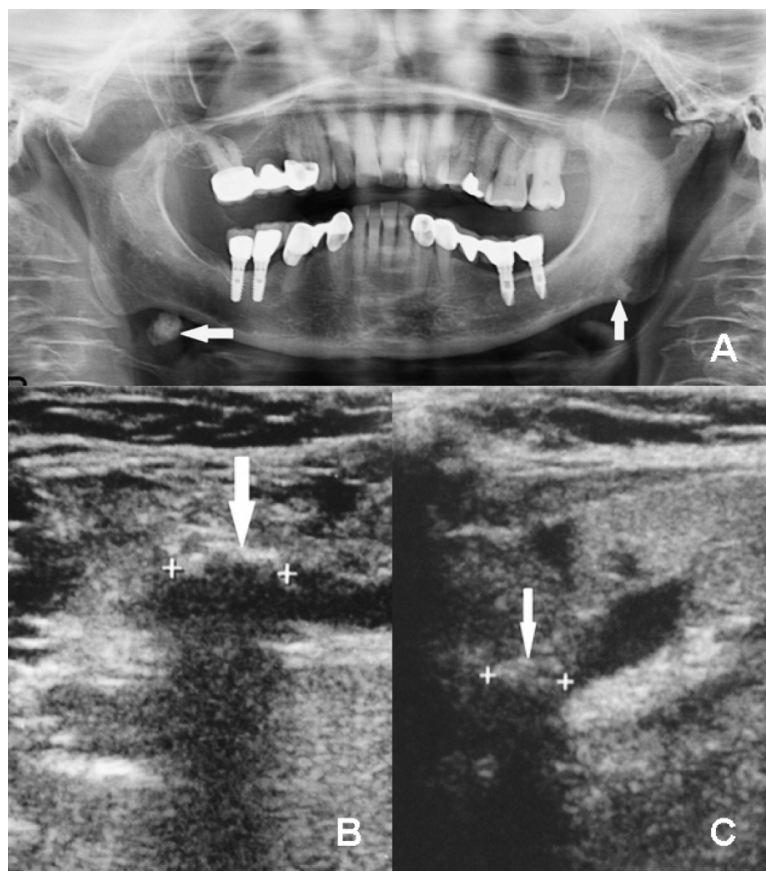

Resim 1. Birinci olguya ait radyografik ve ultrasonografik görüntüler, A: Panoramik görüntüde sağda mandibular basisin inferiorunda ve solda mandibula angulus bölgesine süperpoze olan radyoopasiteler (oklar), B: Ultrasonografide sağ Wharton kanalında, kanalı tam olarak tıkamayan yaklaşık $9.5 \mathrm{~mm}$ boyutundaki hiperekoik alan (ok), C: Ultrasonografide sol Wharton kanalında, kanalı tam olarak tıkamayan yaklaşık $7.5 \mathrm{~mm}$ boyutundaki hiperekoik alan (ok)

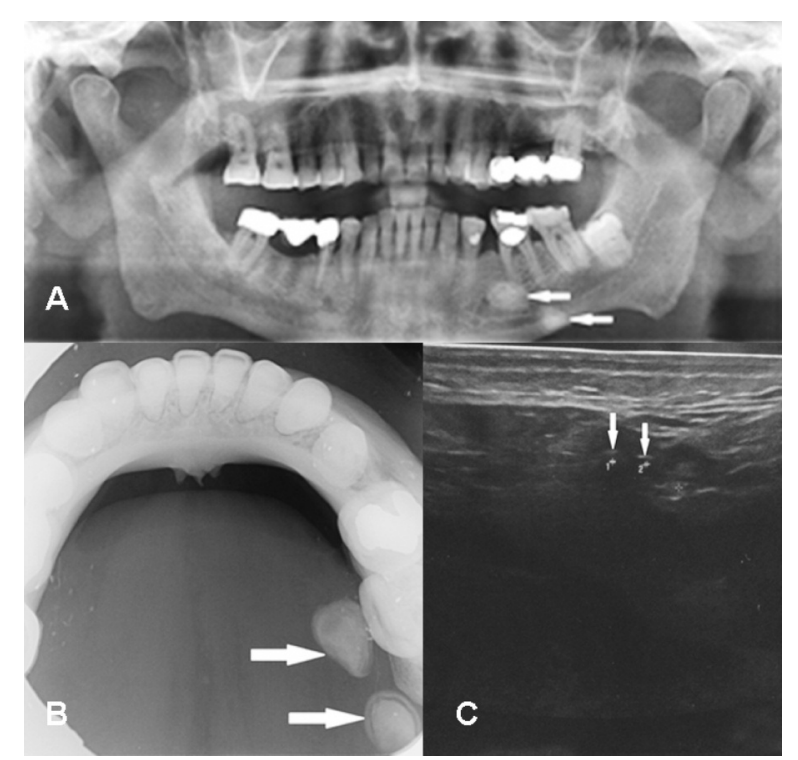

Resim 2. Ikinci olguya ait radyografik ve ultrasonografik görüntüler, A: Panoramik görüntüdeki iyi sınırlı radyoopasiteler (oklar), B: Alt oklüzal görüntüdeki iyi sınırlı radyoopasiteler (oklar), C: Sol submandibular bez ultrasonografik görüntüsündeki hiperekojeniteler (oklar)

parotis bezindeki şişlikten kaynaklanan asimetri ve palpasyonda sağ parotis bezinde hassasiyet tespit edildi. Intraoral muayenede Stenon kanal ağzında püy akışı izlendi. Hasta yemek yerken şişliğin arttığını bildirdi. 


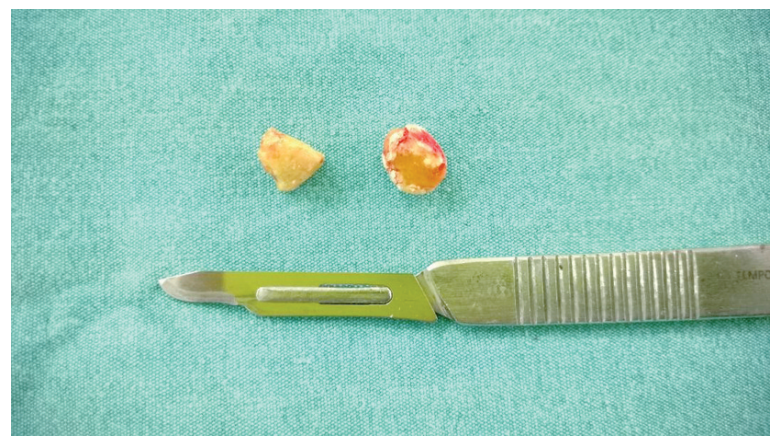

Resim 3. Ikinci olgudaki sialolitlerin eksizyon sonrası görüntüsü

Hasta, ileri görüntüleme amacıyla Gazi Üniversitesi Tıp Fakültesi Radyoloji Anabilim Dalı'na yönlendirildi. Yapılan ultrasonografik incelemede sağ Stenon kanalında $7 \mathrm{~mm}$ boyutunda hiperekoik alan bulunduğu, kanalın distalinin dilate olduğu ve sağ parotis bezinin heterojen ekojeniteye sahip olduğu görüldü (Resim 4).

Parotis bezinde sialolite bağlı sialoadenitis tanısı konulan hastada, genel anestezi altında cerrahi eksizyon ile sialolit çıkarıldı.

\section{TARTIŞMA}

Sialolitler en sık \%80 oranıla submandibular bez kaynaklıdır, bunu \%5-20 ile parotis bezi ve \%1-5 ile sublingual bez izler. ${ }^{2,3}$ Bizim vakalarımızın ikisi submandibular bez, biri parotis beziyle ilişkiliydi. Sialolitler, erkeklerde daha sık gelişmekte ve genellikle 20 yaş ve üzerinde görülmektedir. ${ }^{11}$ Vakalarımızın biri erkek, ikisi kadın; yaşları ise literatürle uyumludur. Yapılan çalışmalarda hastaların \%59'unda ağrı ve şişlik, \%29'unda sadece şişlik ve \%12'sinde sadece ağrı olduğu bildirilmiştir. ${ }^{12} \mathrm{Bu}$ olgu sunumundaki vakaların birinde ağrı ve şişlik olduğu halde diğer ikisinde ağrı veya şişlik mevcut değildi.

Sialolitlerin çoğu direkt radyografi ile görüntülenebilir. Submandibular sialolitlerin \%80-94'ü, parotiste gelişenlerin \%60'ı radyoopak görüntü verir. Bu durumun nedeni sialolitlerin kalsiyum karbonat ve kalsiyum fosfat içerikli oluşudur. ${ }^{13}$ Submandibular sialolitlerin direkt radyografi ile görüntülenmesinde oklüzal ve panoramik radyograflar yarar sağlarken; özellikle parotis bezinde lokalize olan sialolitleri görüntülemek, kemik yapıların örtmesi sebebi ile zor olabilmektedir. ${ }^{13,14}$ Bu sunumda; iki vakadaki submandibular sialolit panoramik radyografta, Stenon kanalında lokalize sialolit periapikal radyografta radyoopak olarak görüntülendi.

Ultrasonografi, klinik olarak sialolit varlığını düşündüren durumlarda ilk görüntüleme seçeneği olarak önerilir. ${ }^{14}$ Ultrasonografinin avantajları arasında maliyetinin çok yüksek olmaması, noninvaziv bir teknik olması ve hastaya radyasyon verilmemesi yer almaktadır. Ultrasonografi ile 2 mm'den büyük boyutta sialolitler $\% 90$ oranında görüntülenebilir. ${ }^{12}$ Bununla beraber ultrasonografi ile radyografta opak olarak görülemeyen sialolitler, sialolitin lokalizasyonu, duktus genişlemesinin varlığı ve iltihabi değişiklikler izlenebilir. ${ }^{13}$ Faydalarının yanında, her zaman kolay ulaşılabilir bir yöntem değildir. Sialolitler; küçük boyutta olmaları, kullanılan cihaz ve probun uygun olmaması, uygulayıcının bilgi ve deneyiminin yetersizliği gibi durumlarda ultrasonografi ile görüntülenemeyebilir. ${ }^{14}$ Yapılan bir çalışmada konvansiyonel radyografi, ultrasonografi, bilgisayarlı tomografi ve bilgisayarlı tomografi rekonstrüksiyonu kıyaslandığında tanı koymada ultrasonografi en başarılı yöntem olarak kabul görmüş; ancak bilgisayarlı tomografi rekonstrüksiyonu ile başka yöntemlerle saptanamayan tek veya multipl sialolitlerin ortaya konabileceği gösterilmiştir. ${ }^{15}$ Manyetik rezonans görüntüleme yöntemi, teknik zorluğu ve pahalı oluşu nedeniyle sialolit için rutinde kullanılmamaktadır. ${ }^{16}$

Sialolit tedavisi, semptomların süresine, semptomların tekrar etme sayısına, sialolitin büyüklüğüne ve lokalizasyonuna bağlıdır. ${ }^{17}$ Lustmann ve ark. ${ }^{18}$ semptom veren sialolitlerin intraoral cerrahi yaklašım ile tedavi edilmesi gerektiggini bildirmislerdir. Kanal ağzına yakın sialolitler, enfeksiyon olmaması durumunda elle manipüle edilerek çıkartılabilir. Posteriorda lokalize olanları çıkartmak için kanal boyunca insizyon yapılması gerekmektedir. ${ }^{6}$ Tedavide, teknolojik gelişmeler sonucu son yıllarda sialolitin kırılması veya endoskopik yöntemler de kullanılmaya başlanmıştır. ${ }^{19}$ Bu sunumda, asemptomatik olan birinci vakanın periyodik takibine karar verildi. Tükürük akış miktarında azalma izlenen ikinci vakada ve ağrı-şişlik ile birlikte eksudasyon izlenen üçüncü vakada sialolitler cerrahi olarak eksize edildi.

\section{SonUç}

Sonuç olarak, sialolitler hastanın anamnez bilgileri, klinik muayene bulguları ve görüntüleme yöntemleri ile birlikte değerlendirilmeli; kalsifiye lenf nodları, vasküler kalsifikasyonlar, uzak kalsifiye neoplazm metastazları gibi yumuşak doku kalsifikasyonlarından ve mandibular torus, osteoma gibi kemik lezyonlarından ayırt edilmeli-

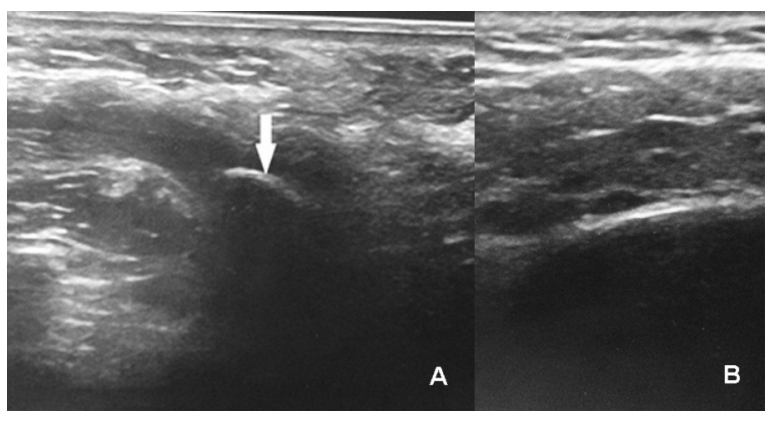

Resim 4. Üçüncü olguya ait ultrasonografik görüntüler, A: Dilate Stenon kanalı ve içerisindeki hiperekoik alan; sialolit (ok), B: Enfekte olan, heterojen ekojenitedeki sağ parotis bezi 
dir. Sialolitlerin teşhisinde doğru görüntüleme yönteminin seçilmesi ve yorumlanması büyük önem taşımaktadır; teşhis ve tedavi aşamaları multidisipliner yaklaşım gerektirir.

\section{TEȘEKKÜR VE ANMA}

Bu makalede yer alan 2 olgu, düzenlenen İstanbul Üniversitesi Diş Hekimliği Fakültesi 7. Uluslararası Bilimsel Kongresi'nde poster olarak sunulmuştur (19-22 Kasım 2014, istanbul).

Çıkar çatışması: Yazarlar bu çalışmayla ilgili herhangi bir çıkar çatışmalarının bulunmadığını bildirmişlerdir.

\section{KAYNAKLAR}

1. Erinanç $A$, Yücel E, Türker M, Delilbaşı E. Tükrük bezi taşları (vaka raporu). GÜ Diş Hek Fak Derg 1984;1:137-41.

2. Hong KH, Yang YS. Sialolithiasis in the sublingual gland. J Laryngol Otol 2003;117:905-7.

3. Liao LJ, Hsiao JK, Hsu WC, Wang CP. Sublingual gland sialolithiasis: a case report. Kaohsiung J. Med Sci 2007;11:590-3.

4. Graziani F, Vano M, Cei S, Tartaro G, Mario G. Unusual asymtomatic giant sialolith of the submandibular gland: a clinical report. J Craniofac Surg 2006;17:549-52.

5. El Deeb M, Holte N, Gorlin RJ. Submandibular salivary gland sialoliths perforated through the oral floor. Oral Surg Oral Med Oral Pathol 1981;51:134-9.

6. Koca H, Alpöz E, Saraç CA, Hepşenol AY, Seçkin T. Sialolitlerin tanı ve tedavisi. Turkiye Klinikleri J Dent Sci 2009;15:228-33.

7. Williams MF. Sialolithiasis. Otolaryngol Clin North Am 1999;32:81934.

8. Scully C, Felix DH. Oral medicine--update for the dental practitioner: dry mouth and disorders of salivation. Br Dent J 2005;199:423-7.

9. Zafersoy Z, Erten Can H, Alasya D, Kahraman G. Genç bireylerde xerostomia görülme sıklı̆ı. GÜ Dişhek Fak Derg 2002;19:31-4.

10. Huang TC, Dalton JB, Monsour FN, Savage NW. Multiple, large siaIoliths of the submandibular gland duct: a case report. Aust Dent $J$ 2009;54:61-5

11. Yu CQ, Yang C, Zheng LY, Wu DM, Zhang J, Yun B. Selective management of obstructive submandibular sialadenitis. Br J Oral Maxillofac Surg 2008;46:46-9.

12. Berçin $S$, Kutluhan $A$, Yurttaş $V$, Kanmaz A. Submandibuler siyalolityazise yaklaşımımız. Yeni Tıp Dergisi 2009;26:16-9.

13. Ayaz YÜ, Dilli A, Hekimoğlu B. Büyük boyutlarda, değişik bir submandibular siyalolityazis olgusu: direkt radyografi ve ultrasonografi bulguları. Ankara Üniv Tıp Fak Derg 2009;62:69-72.

14. Aydın Ü, Yeşildağ A, Oyar O, Gülsoy U. Submandibuler siyalolit tanısında görüntüleme yöntemleri-olgu serisi. GÜ Diş Hek Fak Derg 2004;21:47-52.

15. Avrahami E, Englender M, Chen E, Shabtay D, Katz R, Harell M. CT of submandibular gland sialolithiasis. Neuroradiology 1996;38:28790.

16. Dreiseidler T, Ritter L, Rothamel D, Neugebauer J, Scheer M, Mischkowski RA. Salivary calculus diagnosis with 3-dimensional cone-beam computed tomography. Oral Surg Oral Med Oral Pathol Oral Radiol Endod 2010;110:94-100

17. Yaman $F$, Ünlü $G$, Atılgan $S$. Ağız içine sürmüş submandibular sialolitiazis. Atatürk Üniv Diş Hek Fak Derg 2006;16:70-3.

18. Lustmann J, Regev E, Melamed Y. Sialolithiasis. A survey on 245 patients and a review of the literature. Int. J Oral Maxillofac Surg 1990;19:135-8.

19. Orhan K, Yüksel Y, Doğan N, Üçok Ö. Submandibuler tükrük bezi kanalında iki parçalı tükrük taşı vaka raporu. GÜ Diş Hek Fak Derg 2006;23:189-92

\section{Sialolith: assessment of 3 cases with clinical,} radiographic and ultrasonographic findings

\section{Abstract}

INTRODUCTION: Sialoliths (salivary gland stone) are calcified obstructions that occur in the salivary gland or duct. Sialolith is the most common disease of the salivary glands. Majority of the sialoliths occur in the submandibular gland and can be observed at almost any age. For the diagnosis of sialolith, conventional radiography, ultrasonography and computed-tomography can be used together with clinical examination.

CASE Report: In the first case, radioopacities were seen under the right mandibular corpus and in the left mandibular angulus region on panoramic radiographs of a 66-yearold female patient. Ultrasonographic evaluation showed these radioopacities to be sialoliths. The patient had no other symptoms and was, therefore, followed periodically. The second case was a 61-year-old male patient; in the intraoral examination, hard masses were detected in the left submandibular gland region and no salivary flow was observed in the left Wharton duct. Radioopacities were seen on panoramic and mandibular occlusal radiographs. On ultrasonography, these appeared to be sialoliths and were removed intraorally. The third case was a 55-year-old female patient applied to our clinic with pain on the right cheek and ear while eating. In the intraoral examination, inflammation was detected in the right Stenon duct. On ultrasonography, sialolith and infected parotid gland with heterogeneous echogenicity were noticed. The sialolith was removed surgically under general anesthesia.

CONCLUSION: Application of appropriate imaging techniques are important for the diagnosis of sialolith. The diagnosis and treatment of sialolith requires multidisciplinary clinical approach.

KEYWORDS: Panoramic radiography; sialoliths; ultrasonography 